
\title{
R Research Soure \\ Correlations for Melting Time and Melt Fraction for Bottom Charged Tube in Tube Phase Change Material Heat Exchanger
}

Lanka Sandeep Raj ( $\sim$ lsr.sandeepraj@gmail.com )

JNTUA

Sane Sreenivasulu

Sri Annamacharya Institute of Technology \& Science, Rajampet, India

Bandaru Durga Prasad

JNTUA

\section{Research Article}

Keywords: Latent Heat Storage, Bottom Charging, Numerical Heat Transfer, Computational Phase Change, Melt Fraction Correlation, Melting Time Correlation

Posted Date: December 21st, 2021

DOI: https://doi.org/10.21203/rs.3.rs-1162931/v1

License: (c) (i) This work is licensed under a Creative Commons Attribution 4.0 International License. Read Full License 


\title{
Correlations for Melting Time and Melt Fraction for Bottom Charged Tube in Tube Phase Change Material Heat Exchanger.
}

\author{
Lanka Sandeep Raj*,1,2; Sane Sreenivasulu³; Bandaru Durga Prasad ${ }^{1}$ \\ ${ }^{1}$ Department of Mechanical Engineering, JNTUA, Ananthapuramu, India \\ 2Department of Mechanical Engineering, VNR Vignana Jyothi Institute of Engineering and \\ Technology, Hyderabad, India \\ ${ }^{3}$ Sri Annamacharya Institute of Technology \& Science, Rajampet, India \\ *Corresponding Author, 1sr.sandeepraj@gmail.com
}

\begin{abstract}
:
Multiple factors govern the Thermo-hydraulic behaviour of Latent heat storage devices. The correlation among these factors varies from case to case. In this work, a concentric tube in tube latent heat storage system is numerically modelled for the bottom charging case. Fixed grid enthalpy porosity approach is adopted to account for phase change. The numerical model's independence is achieved by testing mesh size, time step, and maximum iterations per time step. The computational approach is validated against the experimental data. Non-dimensional parameters viz Rayleigh Number $\left(3.04 \times 10^{5}\right.$ to $\left.65.75 \times 10^{5}\right)$, Stefan Number (0.2 to 1), Reynolds Number (600 to 3000 ), and $\mathrm{L} / \mathrm{D}$ ratio (2 to 15 ) are varied in the respective ranges mentioned in parenthesis. Stefan number is found to have a major influence on the Melt Fraction and Melting time, compared to Rayleigh Number and Reynolds Number. Correlations are presented for quantifying the melt fraction and dimensionless melting time.
\end{abstract}

Keywords: Latent Heat Storage, Bottom Charging, Numerical Heat Transfer, Computational Phase Change, Melt Fraction Correlation, Melting Time Correlation.

\section{Introduction}

Energy demand has increased the need for diligent management of energy. Proportionately, Thermal Energy Storage (TES) has attracted a lot of attention in recent decades. TES has the potential to maximize the benefits of the energy sector by storage and intermittent use. Among TES systems, latent heat storage is unique in their ability to provide more heat storage compared to sensible heat storage.

Various kinds [1-17] of latent heat storage devices have been adopted to conserve energy. Multiple parameters influence the design of these latent heat storage devices. It would be handy for designers if these parameters are correlated through mathematical expressions. Efforts made by multiple researchers in this regard are presented hereunder. 
These correlations form two major divisions. The first is nondimensional melting time, i.e., Fourier Number (Fo) equated with one or more dependent parameters. The second one is Melt Fraction (MF), varying from zero to one, expressed in terms of multiple non-dimensional parameters. In this section, Fo correlations are discussed first and followed by MF correlations.

Riley [1] conducted a study on the solidification of metals in cylindrical and spherical systems for Stefan Numbers ranging from 4 to 20. This study has proposed the following mathematical correlation (Eq.1) for solidification time.

$$
F o_{\text {cs }}=0.25+\frac{0.25}{S t}
$$

Eq. 1

Solomon [2] studied various PCMs of melting points in the range of $0^{\circ} \mathrm{C}$ to $58^{\circ} \mathrm{C}$. For $0<\mathrm{St} \leq 4$, different correlations are proposed for cylinder and slab.

$$
\begin{array}{lll}
F O_{\mathrm{cm}}=0.11+\frac{0.25}{S t} & \text { for cylinder } & \text { Eq.2 } \\
F o_{\mathrm{cm}}=0.125+\frac{0.5}{S t} & \text { for slab } & \text { Eq.3 }
\end{array}
$$

Experimental investigations are conducted by Hasan [3] using palmitic acid as Phase Change Material (PCM) in a circular heat storage device using water as Heat Transfer Fluid (HTF). Horizontal and vertical systems are tested for $0.08 \leq \mathrm{St} \leq 0.325$, which yielded the correlation.

$$
F o_{\mathrm{cm}}=0.25+\frac{0.134}{S t}
$$

In continuation to the above work, Hasan [4] employed stearic acid as PCM in a tube in tube system for $0.2 \leq \mathrm{St} \leq 0.357$ and proposed a similar correlation.

$$
F o_{\mathrm{cm}}=0.14+\frac{0.15}{S t}
$$

For cylindrically symmetric regions, Voller [5] numerically predicted non-dimensional melting time for $0.02 \leq \mathrm{St} \leq 0.5$. It can be deduced into the following form.

$$
F o_{\mathrm{cm}}=0.14+\frac{0.25}{S t} \quad \text { Eq.6 }
$$

The above correlations for the dimensionless melting time have considered that Stefan number is the only parameter influencing the melting. Although the Stefan number is a significant influencer, the other parameters also affect the melting time. In this connection, Rathod [6] included the influence of Reynolds number in non-dimensional melting time. Vertical 
Cylindrical Bottom charged tube in tube system considered in this work resulted in the following expression. Paraffin and Water are used as PCM and $\mathrm{HTF}$, respectively, in their work.

$$
F o_{\mathrm{cm}}=0.515\left(S t^{-1.24} R e^{-0.133}\right) \quad \text { Eq.7 }
$$

In extension to the above work, Rathod [7] included one more dimensionless parameter as a ratio of inlet temperature and initial temperature. Paraffin and Stearic acid are used as PCMs. However, this correlation (Eq.8) has resulted in a maximum error of $30.55 \%$.

$$
F o_{\mathrm{cm}}=0.853-3.73 \times 10^{-5}(R e)-0.04778 \mathrm{St} \cdot \frac{T_{\text {inlet }}}{T_{\text {ini }}} \quad \text { Eq. } 8
$$

Kalapala [8] has conducted numerical simulations on a vertical top charged tube in tube system using lauric acid and water. Apart from St and $\mathrm{Re}$, other parameters viz., Rayleigh Number $(\mathrm{Ra})$, Length to Diameter (L/D) ratio, Ratio of Thermal Diffusivities of tube material and $\operatorname{PCM}(\varphi)$ and Tube Thickness to Diameter Ratio ( $\sigma$ ) are also included in the $\mathrm{Fo}_{\mathrm{cm}}$ correlation(Eq.9).

$$
F o_{\text {cm }}=\frac{0.6513(L / D)^{0.3795}}{\operatorname{Re}^{0.06} \mathrm{Ra}^{0.1455} \mathrm{St}^{* 1.111} \varphi^{0.0146}\left(0.7088 \sigma+\frac{0.003}{\sigma}\right)} \quad \text { Eq.9 }
$$

Apart from Fo correlations, MF correlations are also developed by various researchers. Ho and Visakanta [9] have used n-octadecane in a vertical rectangular system and have given the correlation in terms of St, Ra, Fo. Ranges for St and Ra are $0.063 \leq \mathrm{St} \leq 0.132$ and $6.3 \times 10^{7} \leq \mathrm{Ra} \leq 1.4 \mathrm{x}$ $10^{8}$.

$$
M F=0.523\left(R a^{0.25} S t \cdot \mathrm{Fo}\right)^{0.68}
$$

Eq. 10

Fan [10] has employed graphene-based nanocomposite PCMs in a vertical cylindrical system for various loadings, i.e., the weight percentage of nanoparticles. a, b, c values (Eq.11) vary slightly with the given weight percentage. For zero weight percentage, i.e., PCM without nanoparticles, the correlation is Eq. 12.

$$
\begin{gathered}
M F=a \text { Fo St }{ }^{b} a^{c} \\
M F=0.0011 \text { Fo St } t^{0.5} \mathrm{Ra}^{0.276}
\end{gathered}
$$

$\mathrm{Xu}[11]$ employed a porous copper foam fin in a horizontal tube in tube system. Potassium carbonate in binary form is used as a PCM. Eq.13 is obtained in their work to quantify Melt Fraction.

$$
\begin{gathered}
\mathrm{MF}=0.596 \mathrm{X}+0.0438 \mathrm{X}^{2}-0.0825 \mathrm{X}^{3}+0.0130 \mathrm{X}^{4} \\
\text { Where } \mathrm{X}=\text { St.Fo.Ra }{ }^{1 / 8}
\end{gathered}
$$

Along with Fo (Eq.9), Kalapala [8] has obtained MF correlation as given below (Eq. 14). 


$$
\mathrm{MF}=\left[\frac{0.1 \mathrm{Fo} \mathrm{Re}^{0.064} \mathrm{Ra}^{a} \mathrm{St}^{* 0.0106} \phi^{0.0106}\left(21.178 \sigma+\frac{0.1}{\sigma}\right)}{(L / D)^{0.3795}}\right]^{0.7} \quad \text { Eq. } 14
$$

Where

$\mathrm{St}^{*}=\frac{C_{p_{S}}\left(T_{m}-T_{i n i}\right)+C_{p_{l}}\left(T_{\text {inlet }}-T_{m}\right)}{L}$

$a=\left\{\begin{array}{cc}\frac{e^{\omega(L / D)^{0.04}}}{4.2} & \text { if } \omega \leq 0.35 \\ 0.1(L / D)^{0.025} & \text { if } 0.35 \leq \omega \leq 0.74 \\ \frac{0.08(L / D)^{0.025}}{\omega} & \text { if } \omega>0.74\end{array}\right.$

$\varphi=$ Ratio of Thermal Diffusivities $=\frac{\alpha_{\text {tube material }}}{\alpha_{P C M}}$

$\sigma=$ Tube Thickness to Diameter Ratio $=\frac{\delta}{D_{\text {shell }}}$

$\omega=$ Fo.St 0.6

So far, various correlations available in the literature are summarized. Among these, Kalapala [8] did a detailed analysis on the influence of each dimensionless parameter on melting for the Top Charging case. In this present work, a similar attempt is made to understand the impact of dimensionless parameters in Bottom Charging and to establish the correlation for the Bottom charging case.

Kalapala [8] has considered correlation among Melt Fraction, St, Fo, Ra, $\operatorname{Re}, \varphi, \sigma$, and L/D ratio. However, in the same work [8], it has been concluded that the parameters $\varphi$, and $\sigma$, had a negligible effect on total melting time. Considering this finding, in the present work, these two parameters are not considered. 


\section{Numerical Model and Solution Procedure}

\subsection{Numerical Model}
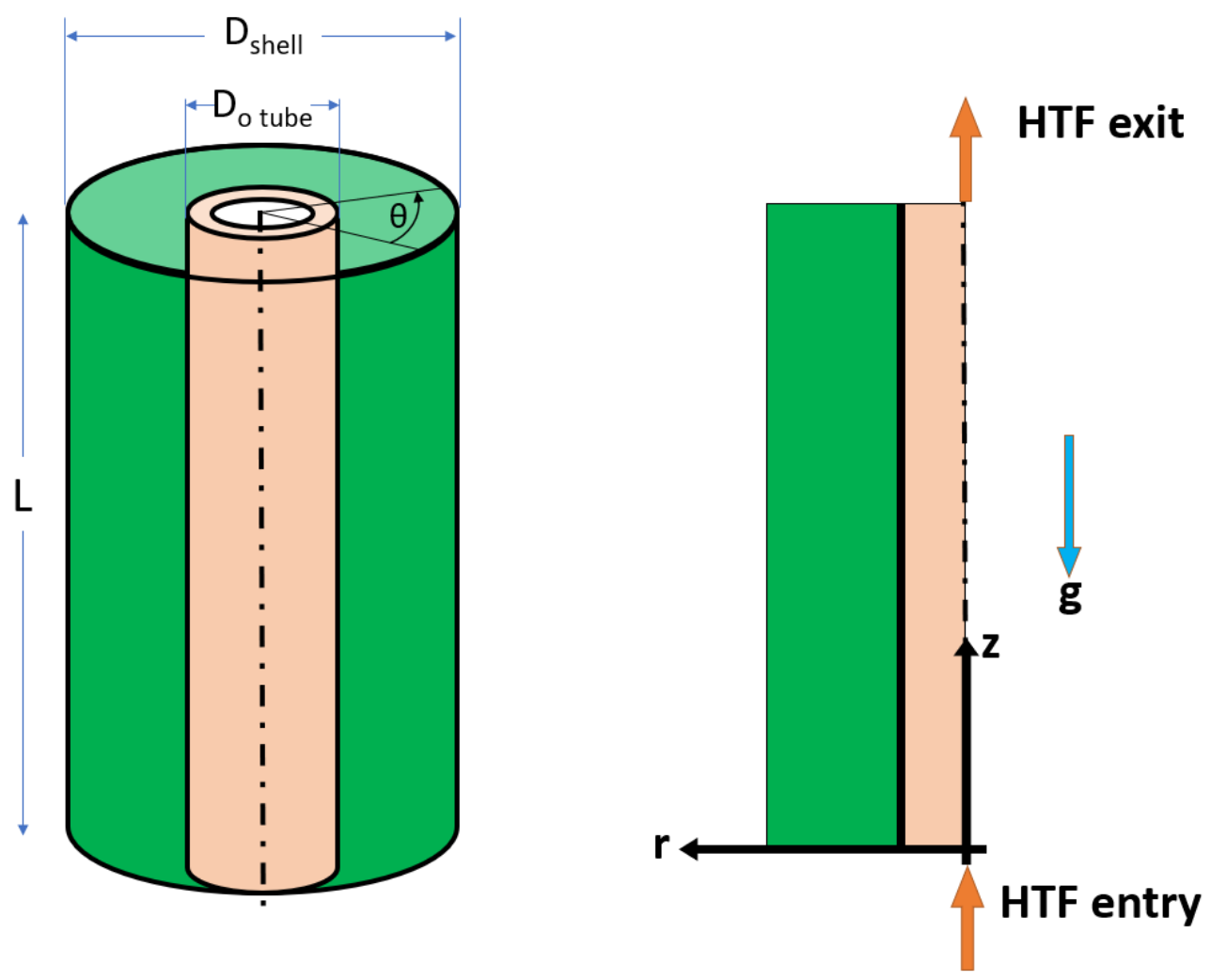

Fig.1. Numerical Model Description

As shown in Fig.1, the outer tube and inner tube are placed concentrically. The inner tube facilitates the HTF (water) flow. Space between tubes is filled with PCM.

For a cylinder in cylinder geometry, Longeon [12] has proved through experiments that the temperature does not significantly vary with the angle $(\theta)$ in any horizontal plane. Temperature variation is significant only in radial direction $(r)$ and axial direction $(z)$. So, in this work, the $2 \mathrm{D}$ axisymmetric domain is selected for performing the simulations, which reduces the computational load substantially compared to a 3D domain. HTF is made to flow in the opposite direction to gravity, as shown in Fig.1, to conform to bottom charging.

Thermophysical properties of the RT35 PCM (Table.1) used by Longeon [12] are adopted in this numerical study. 
Table.1. Thermo physical Properties of PCM RT35 [12]

\begin{tabular}{|l|l|}
\hline Melting Point & $35^{0} \mathrm{C}$ \\
\hline Latent Heat & $157 \mathrm{~kJ} / \mathrm{kg}$ \\
\hline Density & $760 \mathrm{~kg} / \mathrm{m}^{3}$ \\
\hline Thermal Expansion Coefficient & $0.001 \mathrm{~K}^{-1}$ \\
\hline Specific Heat & $1.8(\mathrm{~s}) ; 2.4(1) \mathrm{kJ} /(\mathrm{kg} . \mathrm{K})$ \\
\hline Thermal Conductivity & $0.2 \mathrm{~W} / \mathrm{m} . \mathrm{K}$ \\
\hline Kinematic Viscosity & $3.3 \times 10^{-6} \mathrm{~m}^{2} / \mathrm{s}$ \\
\hline
\end{tabular}

\subsection{Solution Procedure}

The governing mathematical equations are built based on the following assumptions.

- $\mathrm{PCM}$ is pure, homogeneous, isotropic, and is in thermodynamic equilibrium in solid and liquid form.

- PCM flow during melting is inviscid, laminar, unsteady, and incompressible.

- PCM melting is two-dimensional and axisymmetric.

- The Boussinesq assumption approximates PCM density variation.

Melting and Solidification model in CFD software Ansys Fluent is used to simulate the numerical melting. The following governing equations are considered for solving the same by employing the Enthalpy and Porosity technique [13].

2.2.1 Continuity Equation:

$$
\frac{1}{r} \frac{\partial(r u)}{\partial r}+\frac{\partial v}{\partial z}=0
$$

Continuity Equation is adopted in the form of Eq. 15 for this numerical model. Since density variation is modelled with Boussinesq Approximation, the continuity equation is considered neglecting the change in density and thus the corresponding transient term. As this is a $2 \mathrm{D}$ domain, theta $(\theta)$ terms are also ignored.

\subsubsection{Momentum Equations:}

r - momentum equation:

$$
\rho\left[\frac{\partial u}{\partial t}+u \frac{\partial u}{\partial r}+v \frac{\partial u}{\partial z}\right]=-\frac{\partial p}{\partial r}+\mu \frac{\partial^{2} u}{\partial r^{2}}+\mu \frac{1}{r} \frac{\partial}{\partial r}\left(r \frac{\partial u}{\partial r}\right)-\mu \frac{u}{r^{2}}+A u
$$


Z-momentum equation:

$$
\rho\left[\frac{\partial v}{\partial t}+u \frac{\partial v}{\partial r}+v \frac{\partial v}{\partial z}\right]=-\frac{\partial p}{\partial z}+\mu \frac{\partial^{2} v}{\partial z^{2}}+\mu \frac{1}{r} \frac{\partial}{\partial r}\left(r \frac{\partial v}{\partial r}\right)+A v+S_{b}
$$

In momentum equations, $\theta$ components are nullified owing to $2 \mathrm{D}$ simplification. As density $(\rho)$ variation is minimal w.r.t change in temperature, it can be taken out of the partial derivative. Similarly, since the PCM flow is inviscid, the viscosity term is also considered out of the derivative.

These are Navier stokes equations, except for the terms 'Au', 'Av' and ' $\mathrm{S}_{\mathrm{b}}$.' These source terms are added to account for the phase change and buoyancy effect.

$$
A=-C^{*} \frac{(1-\epsilon)^{2}}{\epsilon^{3}+b}
$$

Among all these equations, ' $A$ ' is the crucial term accounting for the phase transition. ' $A$ ' will serve two purposes here. The first purpose is to represent the solid phase by $A=0$. To attain zero, the $(1-\varepsilon)$ term is taken in the numerator as the porosity $(\varepsilon)$ is 1 in the solid phase.

'A' (Eq.18) is essentially a Carman Kozeny equation [14] with a mushy constant $\mathrm{C}^{*}$. The second purpose is to mimic the momentum equations with the Carman-Kozeny equation of porous media flow, thus quantifying phase change.

Hameter [15], Kumar [16], in their studies, have concluded that the variation in the constant $C^{*}$ has a significant influence on the thermohydraulic behaviour of PCM. C* is a morphological constant (or mushy zone constant) that indicates the melting front's structure and pattern. Its value is chosen as $10^{6}$ in this work, as the recommended range is between $10^{4}$ to $10^{7}[18]$.

'b' with 0.001 value is added in the denominator to avoid the 'Undefined Number' error if $\varepsilon$ equates to zero.

$$
S_{b}=\rho_{\text {ref }} \mathrm{g} \beta \Delta \mathrm{T}
$$

$\mathrm{S}_{\mathrm{b}}$ is a buoyancy source term incorporated into the $z$-momentum equation. This term is obtained based on the Boussinesq approximation, where $\rho_{\text {ref }}$ is the reference density, $g$ is the gravitational acceleration, $\beta$ is the coefficient of thermal expansion, and $\Delta \mathrm{T}$ is the temperature difference.

\subsubsection{Energy Equation}

$$
\rho\left[\frac{\partial h}{\partial t}+u \frac{\partial h}{\partial r}+v \frac{\partial h}{\partial z}\right]=\frac{k}{C_{p}}\left[\frac{\partial^{2} h}{\partial z^{2}}+\frac{1}{r} \frac{\partial}{\partial r}\left(r \frac{\partial h}{\partial r}\right)\right]+S_{h}
$$


Energy equation (Eq.20) is written essentially in terms of sensible enthalpy. Density is considered constant owing to incompressible flows. Thermal conductivity is deemed to be constant as the PCM is assumed to be homogeneous and isotropic.

$$
S_{h}=\frac{\partial(\rho \Delta h)}{\partial t}+\vec{\nabla} \cdot(\rho \vec{V} \Delta h)
$$

Latent enthalpy $(\Delta \mathrm{h})$ is blended in the Source term $\mathrm{S}_{\mathrm{h}}$ (Eq.21). This is temperature-dependent property. If PCM temperature is less than Solidus, $\Delta \mathrm{h}$ value is zero. Whenever PCM temperature crosses liquidus, $\Delta \mathrm{h}$ is equal to PCM latent heat. In greater than solidus and less than liquidus range, $\Delta \mathrm{h}$ is a fraction of L, quantified as shown below (Eq.22).

$$
\Delta h=\left\{\begin{array}{cc}
0 & \text { if } T<T_{s} \\
\frac{L\left(T-T_{S}\right)}{\left(T_{l}-T_{S}\right)} & \text { if } T_{s} \leq T \leq T_{l} \\
L & \text { if } T \geq T_{l}
\end{array}\right.
$$

The Finite Volume Method is employed in the CFD Analysis, while the SIMPLE algorithm does the pressure and velocity coupling. PRESTO and QUICK schemes are used for discretization of pressure and momentum, respectively. Under relaxation factors are chosen as $0.3,1,1,0.7,0.9,1$ for pressure, density, body forces, momentum, liquid fraction update, energy, respectively.

\section{Model Independence and Experimental Validation}

\subsection{Model Independence}

The numerical model built is checked for its Independence. Independence is established using three criteria, i.e., Mesh size, Time Step, and the Maximum number of iterations per Time Step.

\subsubsection{Mesh Independence}

Simulations are performed with three different mesh sizes with 10,025 nodes, 18,847 nodes, and 37,647 nodes. As shown in Fig.2, 10,025 nodes mesh varied by less than $7 \%$ from the other two for the mass fraction of 0.3 to 0.75 . Mass Fraction is matching with each other in 18,847 nodes mesh and 37,647 nodes throughout the calculation. The total simulation run time is doubled in the case of 37,647 nodes compared to 18,847 nodes. So, to save time, the 18,847 nodes mesh is chosen in this work. 


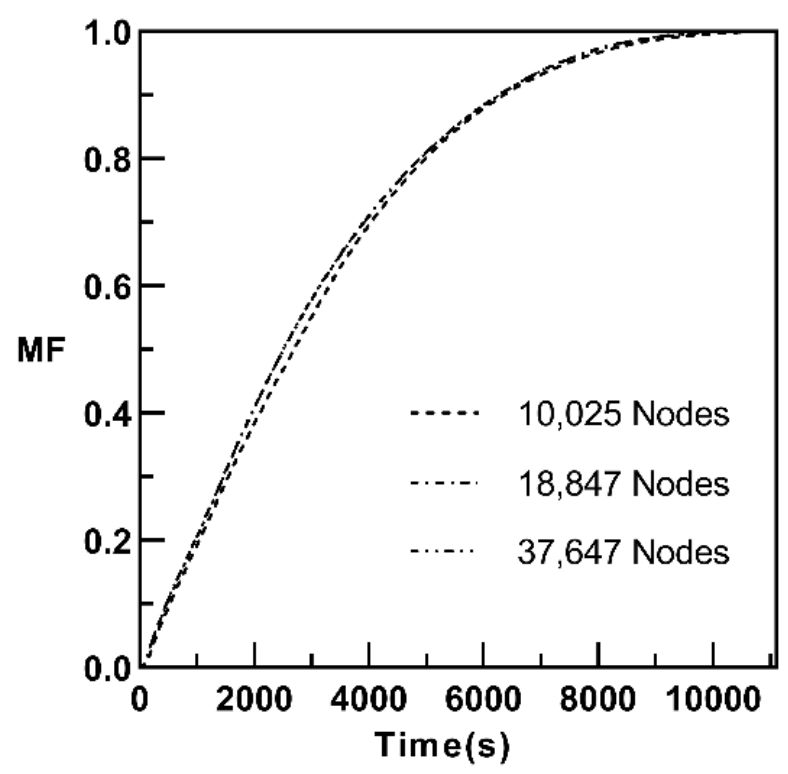

Fig.2. Mesh - Independence Test

\subsubsection{Time Step Independence}

To authenticate the Time Step independence, simulations were carried out at 18,847 nodes mesh with four different time steps viz. 0.025, 0.05, 0.1 and 0.5. The outcome in Fig. 3 indicates that the Mass Fraction is matching in all four cases. As the Time Step size decreases, the overall simulation time increases. On the other hand, if the time step is large, it may result in erroneous simulation. To settle these inferences, 0.1 is chosen as Time Step in this study.

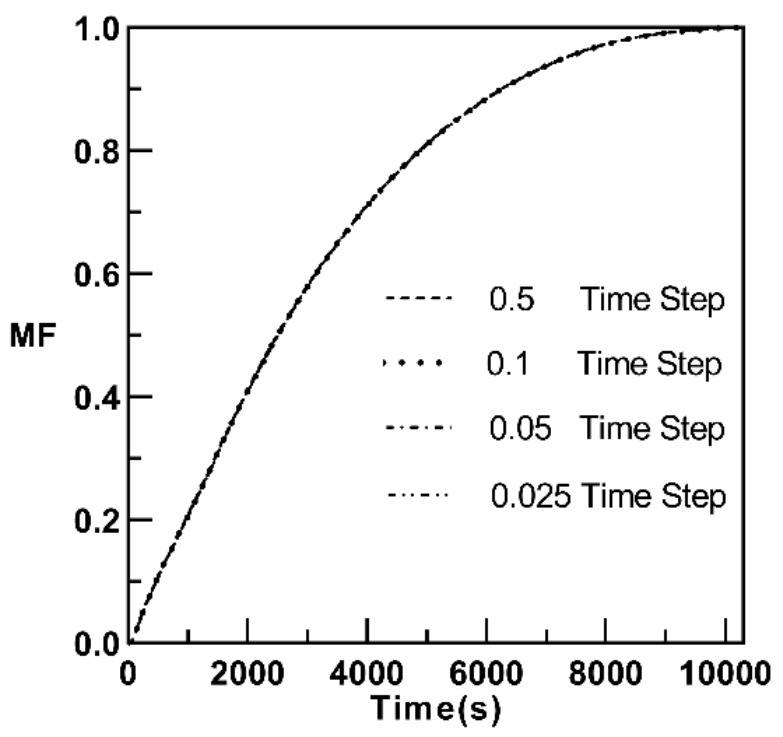

Fig.3. Time Step - Independence Test 
The converged solution is obtained only when the simulation is converged at every time step. In order to get the convergence at each time step, the Maximum number of Iterations per Time Step has to be chosen appropriately. So as to verify the influence of this, Five cases are tested viz 5,10,20,30 and 50, for 18,847 nodes mesh and 0.1-time step. As Fig.4 suggests, the Mass Fraction is identical in all cases. Keeping total simulation time and other parameter variations in perspective, 20 Maximum Iterations per Time Step is chosen.

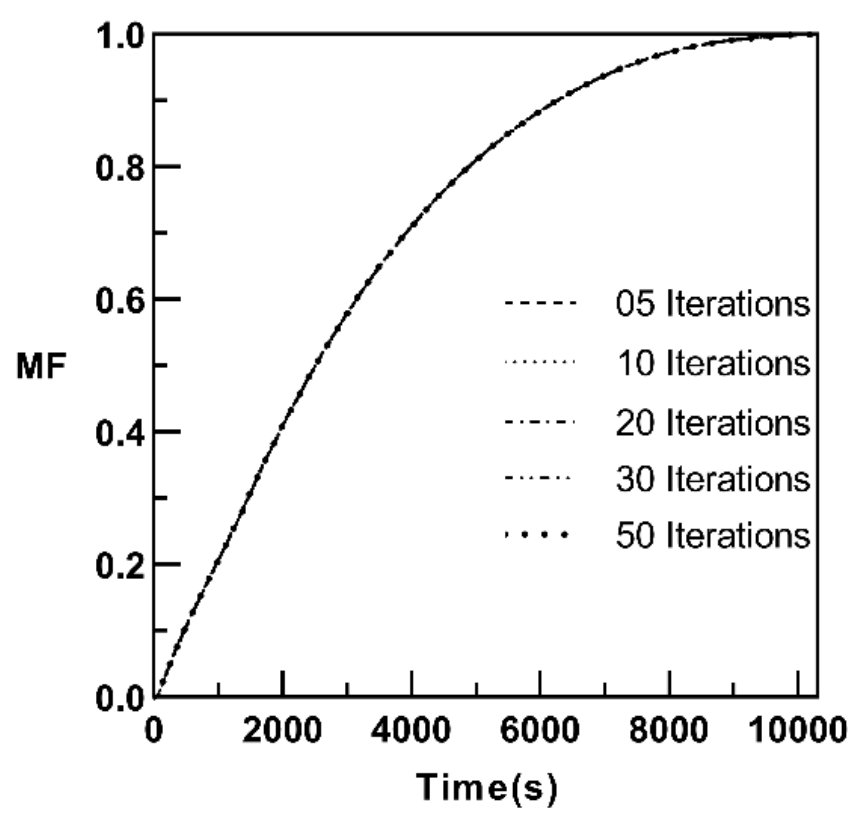

Fig.4. Maximum Iterations per Time Step - Independence Test 


\subsection{Experimental Validation}

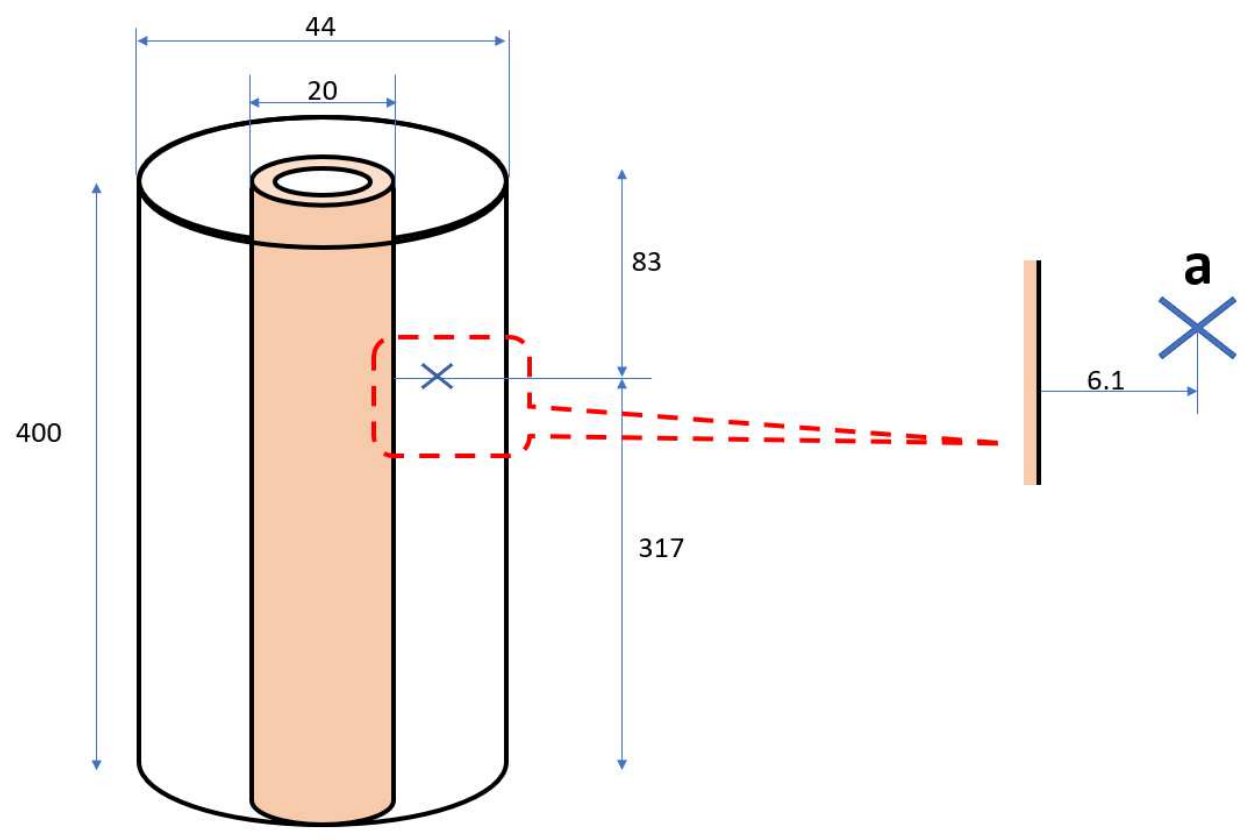

Fig.5. Dimensions (in $\mathrm{mm}$ ) of test domain and Temperature position in space considered for experimental validation [12].

Longeon [12] conducted experiments for Bottom charging and plotted temperature evolution in RT35 PCM. As indicated in Figure 5, the temperature at point "a" is tracked. Fig.6. shows that the numerical temperature variation is consistent with the experiment. It is to be noted that the dimensions given in Fig. 5 are for experimental validation purpose only.

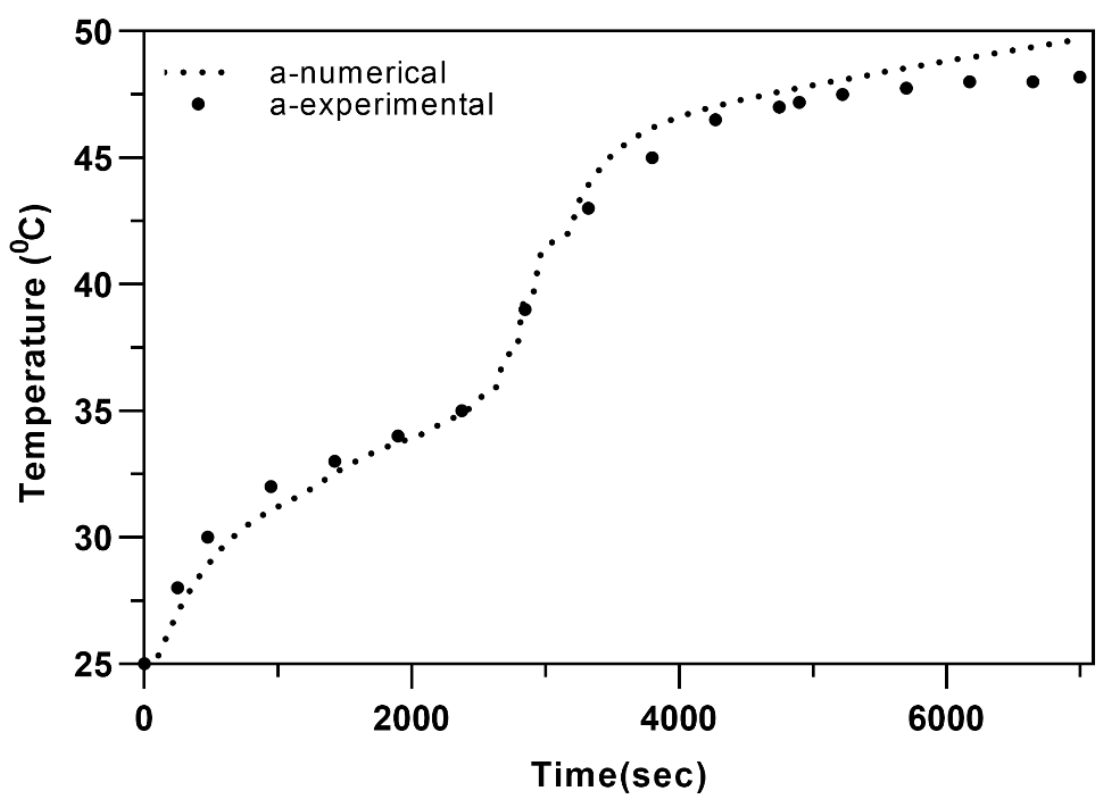

Fig.6. Numerical Vs. Experimental Temperature Progression 
Table.2. Non-Dimensional Numbers formulae and ranges

\begin{tabular}{|l|c|c|}
\hline $\begin{array}{l}\text { Non-Dimensional } \\
\text { parameter }\end{array}$ & Formula & Range \\
\hline Stefan Number & $S t=\frac{C_{P}\left(T_{\text {inlet }}-T_{m}\right)}{L}$ & 0.2 to 1.0 \\
\hline Rayleigh Number & $R a=\frac{g \beta\left(T_{\text {inlet }}-T_{m}\right)\left(R_{\text {shell }}-R_{\text {otube }}\right)^{3}}{\vartheta \cdot \alpha}$ & $3.04 \times 10^{5}$ to $65.75 \times 10^{5}$ \\
\hline Reynolds Number & $R e=\frac{v\left(D_{\text {tube }}\right)}{\vartheta_{\text {HTF }}}$ & 600 to 3000 \\
\hline Fourier Number & Fo $=\frac{\alpha \cdot t}{\left(R_{\text {shell }}-R_{\text {otube }}\right)^{2}}$ & - \\
\hline L/D ratio & L/D $=$ length of shell $/$ diameter of shell & 2 to 15 \\
\hline
\end{tabular}

\section{Results and Discussion}

To understand the thermo-hydraulic behaviour of PCM in concentric shell and tube heat exchanger, dimensionless parameters viz Rayleigh Number, Stefan Number, Reynolds Number, and L/D ratio are varied by varying respective physical properties. Table. 2 shows how each dimensionless parameter is quantified. In this section, the effect of each parameter is analysed, and correlation among them is presented.

\subsection{Variation of Rayleigh Number}

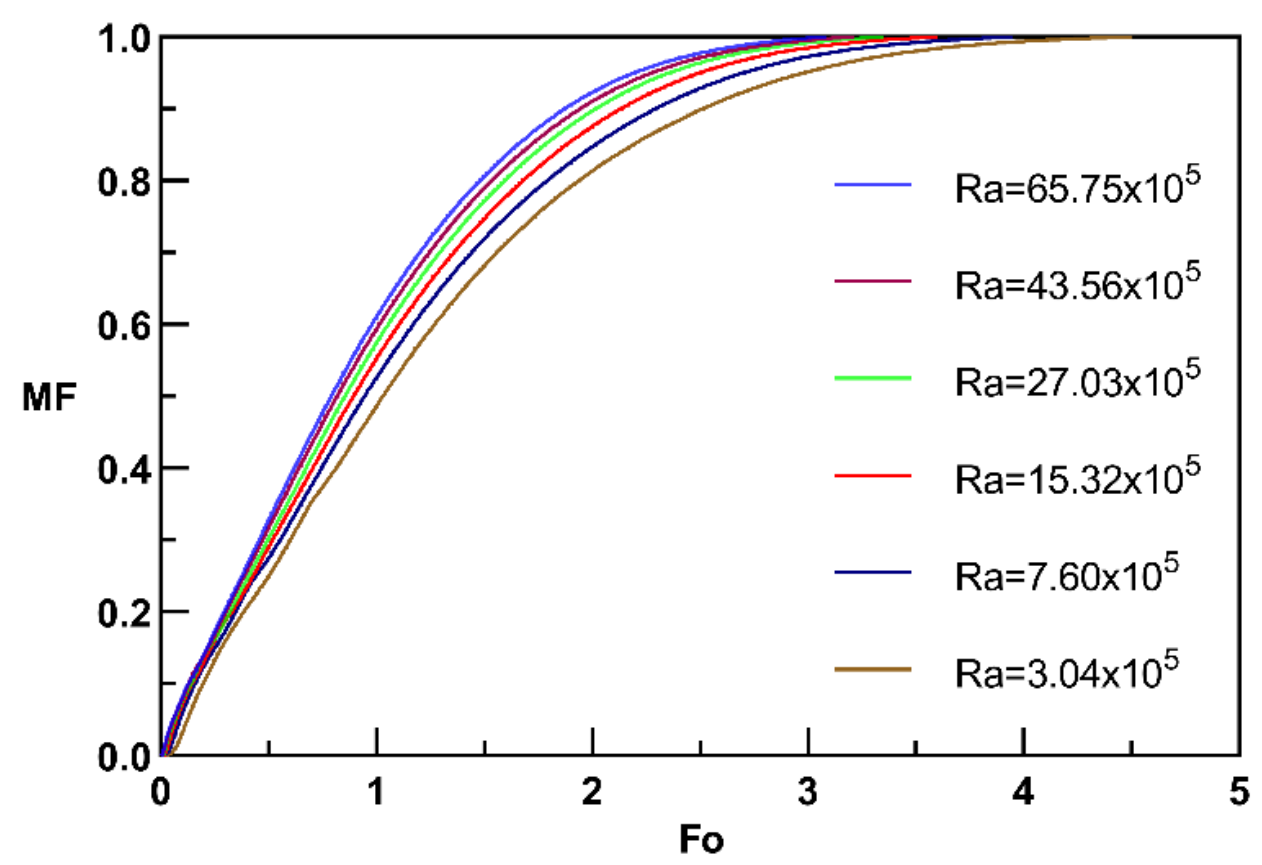

Fig.7.Fo Vs. MF Variation with Rayleigh Number 


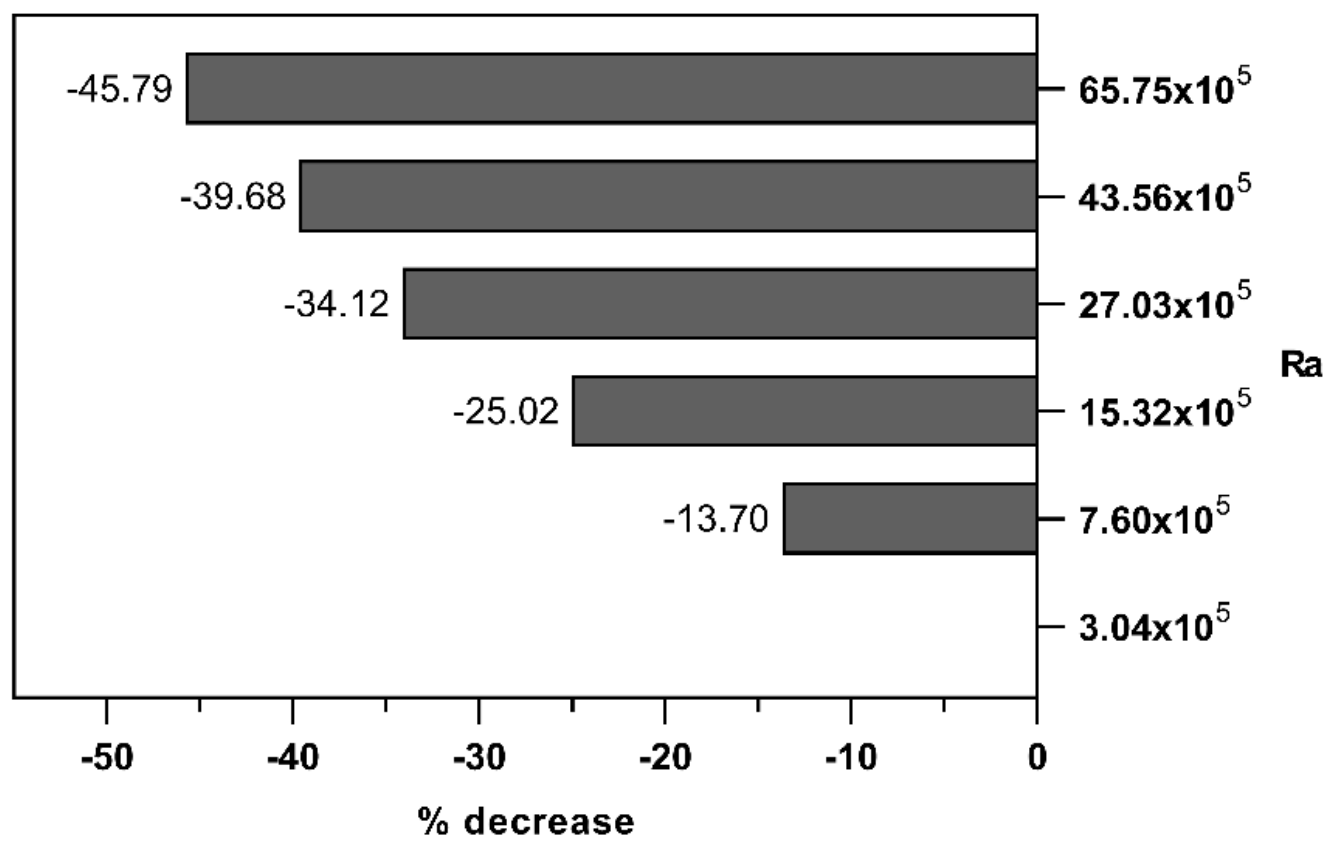

Fig.8. Percentage decrease in $\mathrm{Fo}_{\mathrm{cm}}$ w.r.t $\mathrm{Ra}=3.04 \times 10^{5}$

Rayleigh Number characterizes the buoyancy-driven fluid flow and heat flow. In natural convection, the Rayleigh Number establishes the interrelationship of Buoyancy force with Viscous force. The increase in Rayleigh Number indicates the increase in the dominance of buoyant forces over the viscous forces. In this work, Ra numbers considered are $3.04 \times 10^{5}$, $7.6 \times 10^{5}, 15.32 \times 10^{5}, 27.03 \times 10^{5}, 43.56 \times 10^{5}$ and $65.75 \times 10^{5}$. These numbers are obtained by varying the diameter of the shell. Other dimensionless parameters are maintained constant at $\mathrm{Re}=1500 ; \mathrm{St}=0.5 ; \mathrm{L} / \mathrm{D}=9$.

Fig.7 shows the Rayleigh Number Effect on melt fraction and dimensionless time. The plot suggests that the increase in Rayleigh Number decreases the dimensionless melting time. However, the rise in Rayleigh Number will increase the actual melting time, as the amount of PCM will increase with the increase in shell diameter. The Rayleigh Number trend points to the increased influence of buoyancy force over the viscous force, which is resulting in the reduction of non-dimensional melting time. It has been observed that the increase in Rayleigh Number from $3.04 \times 10^{5}$ to 65.75 $\mathrm{x} 10^{5}$ decreased the non-dimensional time by $45.79 \%$ (Fig.8). 


\subsection{Variation of Stefan Number}

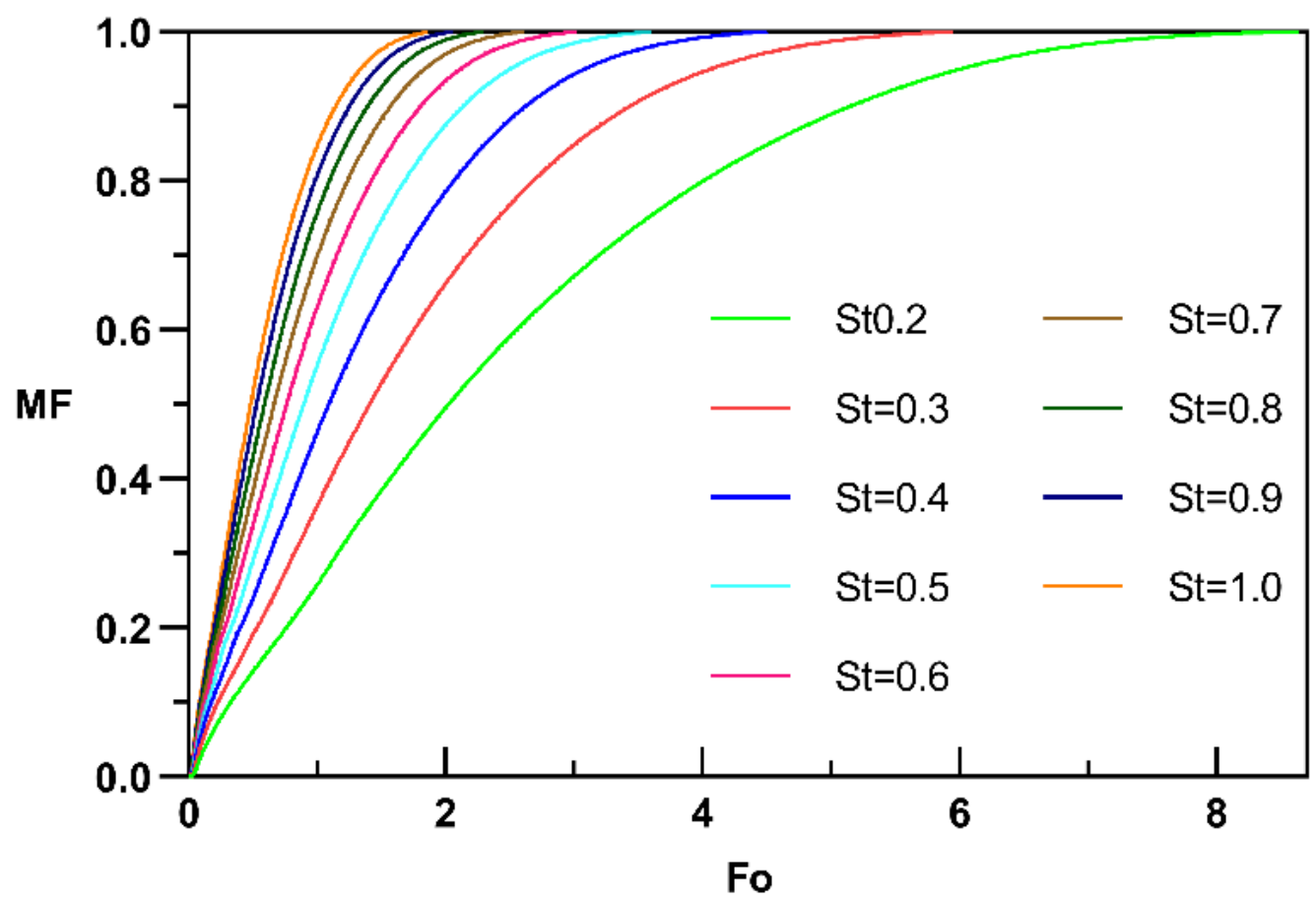

Fig.9. Fo Vs. MF Variation with Stefan Number

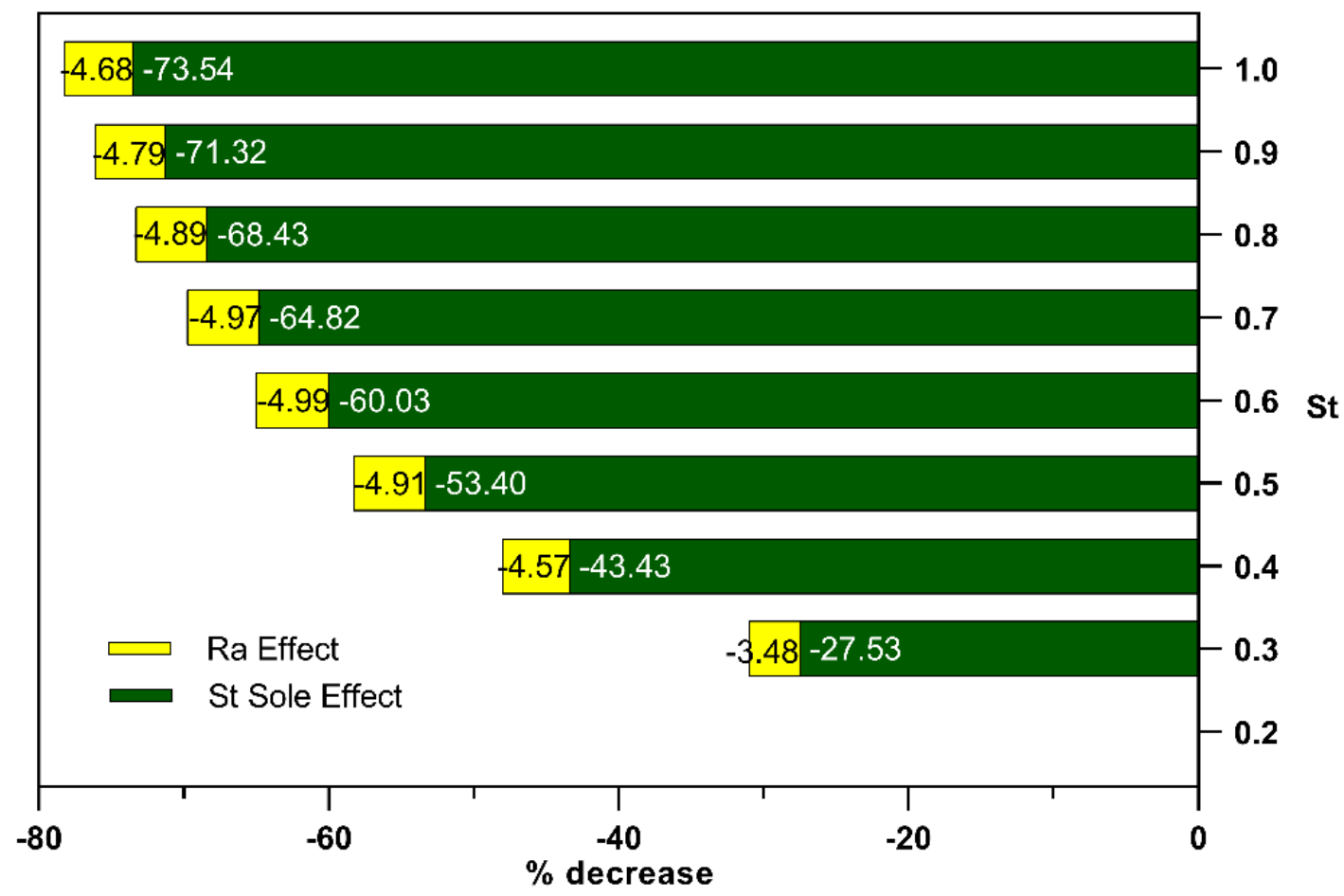

Fig. 10. Percentage decrease in $\mathrm{Fo}_{\mathrm{cm}}$ w.r.t $\mathrm{St}=0.2$ 
Stefan Number quantifies the sensible heat to latent heat proportion in a given PCM. In this work, Stefan Number is varied from 0.2 to 1 in steps of 0.1 by changing the HTF inlet temperature. Other parameters are kept constant at $R e=1500$ and $L / D=9$. Fig. 9 shows the melt fraction evolution as the Stefan Number varies. But, due to the variation in HTF inlet temperature in each case, the Rayleigh Number also varies with Stefan Number. In order to counter-balance the Rayleigh variation, the expression $\mathrm{Fo}_{\mathrm{cm}} \cdot \mathrm{Ra}^{\mathrm{n}}$ is found to have values very close to each other at $\mathrm{n}=0.1215$. Thus, $\mathrm{Fo}_{\mathrm{cm}} \cdot \mathrm{Ra}^{\mathrm{n}} V \mathrm{~s}$. MF plot (Fig.11) gives the exclusive influence of Stefan Variation on melting.

From Fig.11, it is observed that a lesser Stefan Number will result in increased time for PCM melting. This is obvious because lesser the Stefan Number, lesser the HTF inlet temperature. Moreover, the lesser the HTF inlet temperature, greater the melting time as the PCM melts only due to the hightemperature source, i.e., HTF.

Fig. 10 shows the percentage reduction in the non-dimensional melting time from $\mathrm{St}=0.3$ to $\mathrm{St}=1.0$, with respect to $\mathrm{St}=0.2$. For the $\mathrm{St}=1.0$ case, the total percentage reduction is $78.22 \%$. In this, the sole effect of St is $73.54 \%$, and the remaining $4.68 \%$ is the Ra effect. Likewise, in all cases, the St effect is higher than Ra. From this, it can be inferred that Stefan Number has a dominant impact on melting compared to Rayleigh number.

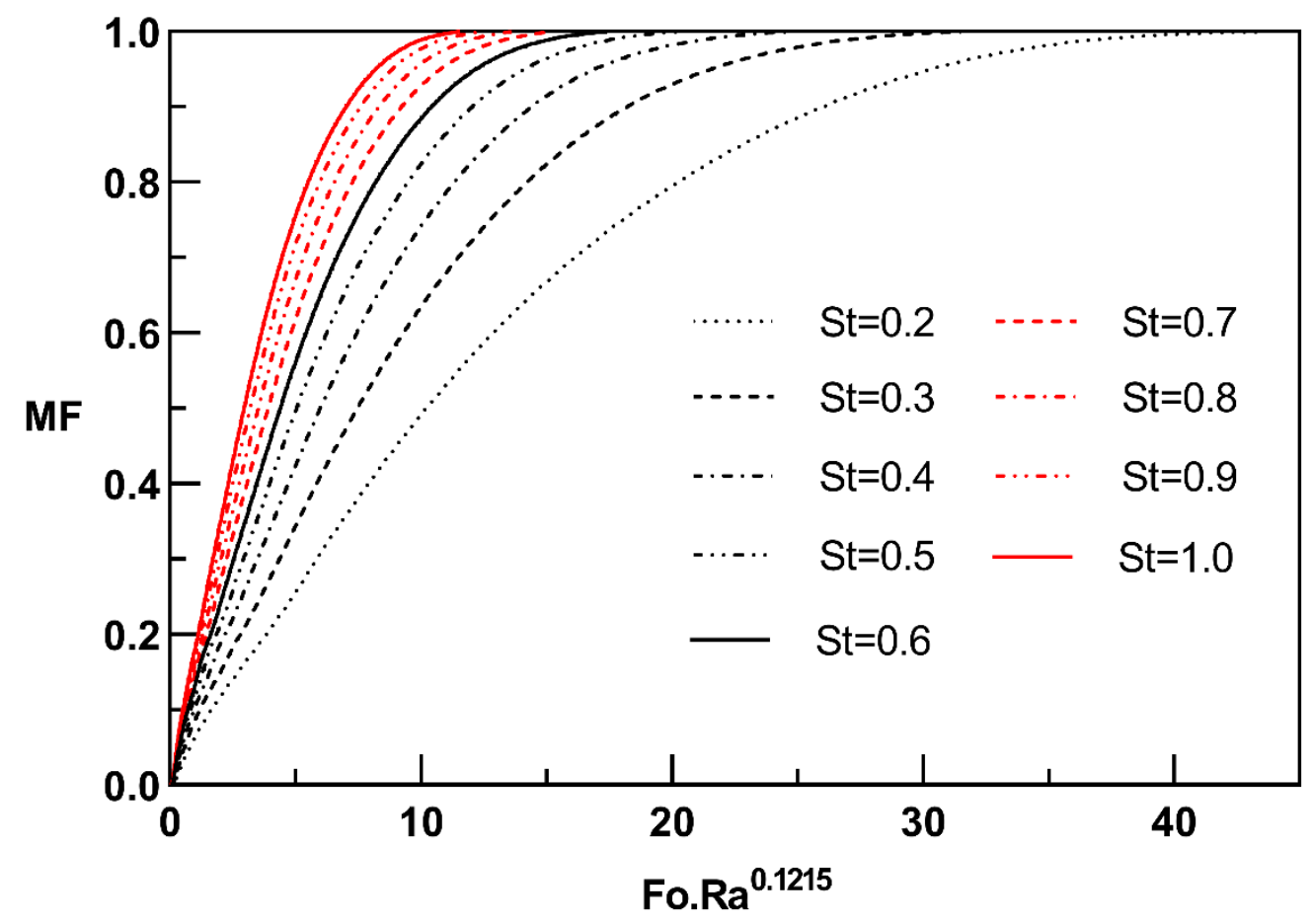

Fig.11. Fo.Ra ${ }^{0.1215}$ Vs. MF Variation with Stefan Number 


\subsection{Variation of Reynolds Number}

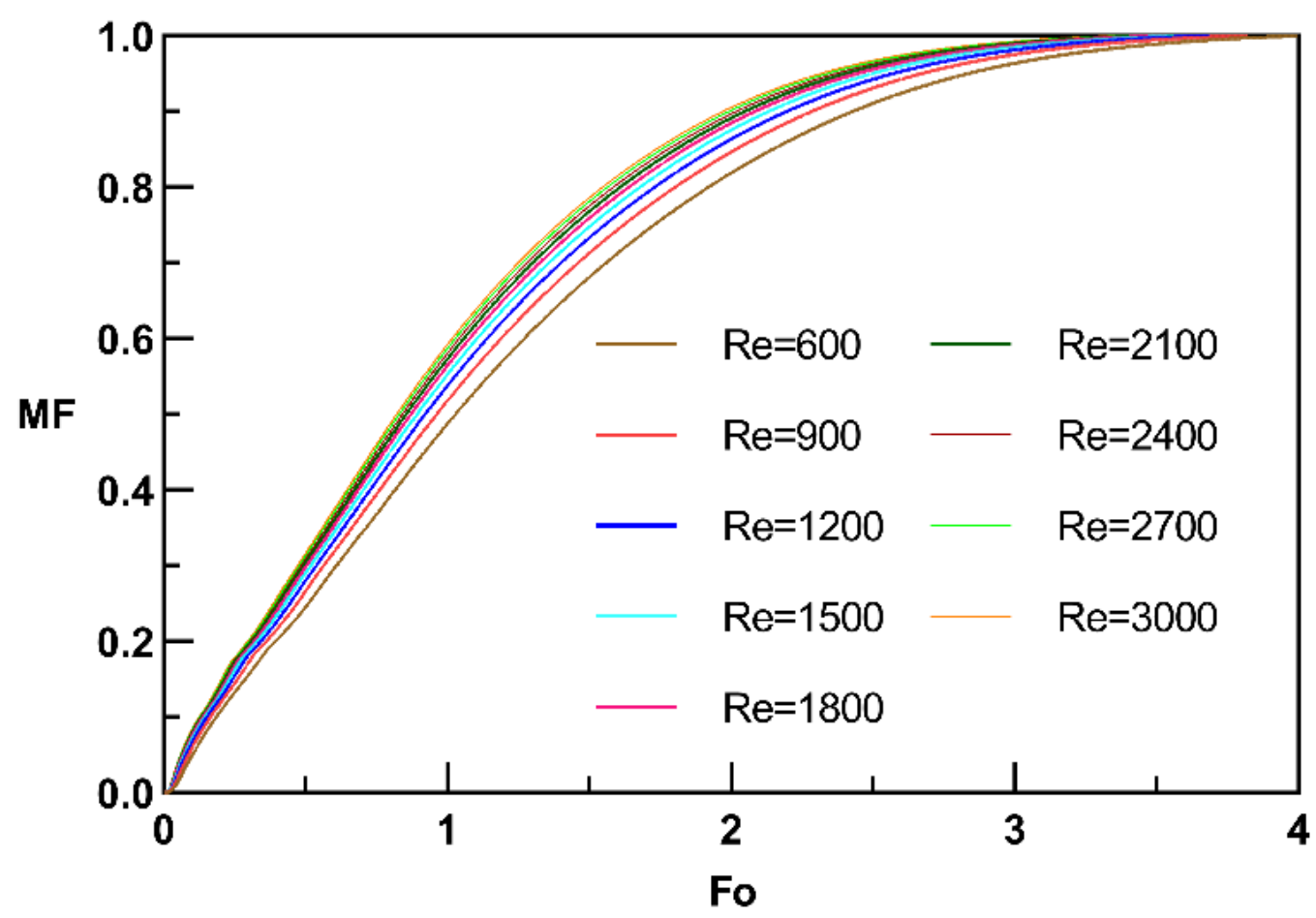

Fig.12. Fo Vs. MF Variation with Reynolds Number

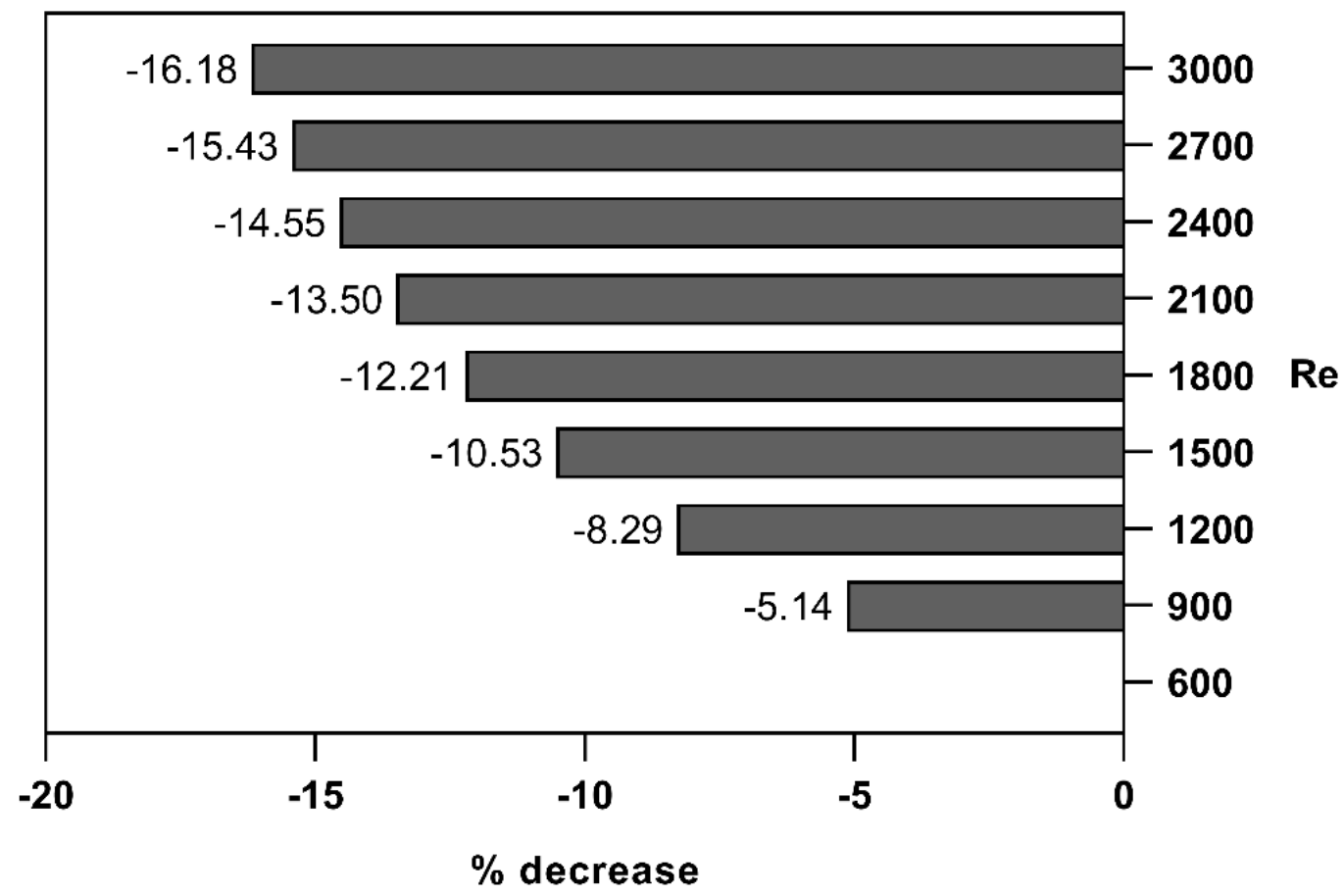

Fig. 13. Percentage decrease in $\mathrm{Fo}_{\mathrm{cm}}$ w.r.t $\mathrm{Re}=600$ 
Reynolds number is solely related to HTF and physically represents its velocity. However, it impacts the forced convection heat transfer between HTF and the inner pipe. Thus, the melting of PCM can be influenced by Re. In this work, Re is varied from 600 to 3000 in steps of 300 by varying the mass flow rate of $\mathrm{HTF}$. $\mathrm{St}=0.5, \mathrm{Ra}=15.32 \times 10^{5}$ and $\mathrm{L} / \mathrm{D}=9$ are kept constant.

Fig.12 shows that the increase in Reynolds Number decreased the dimensionless melting time. MF curves for $\mathrm{Re}=1500$ to $\mathrm{Re}=3000$ are very close to each other, indicating decresed Re influence on melting in these Reynolds Numbers. From Fig. 13, it can be understood that the percentage reduction in non-dimensional time with the increase in Re is reducing with every step. Furthermore, the maximum percentage reduction observed is $16.18 \%$. Thus, the influence of $\mathrm{Re}$ is not as significant as the influence of $\mathrm{Ra}$ and St on the melting of PCM.

Percentage reduction from $\mathrm{Re}=900$ to $\mathrm{Re}=1200$ increased from $5.14 \%$ to $8.29 \%$ with $3.1 \%$ increase. But from $\mathrm{Re}=2700$ to $\mathrm{Re}=3000$ increase is from $15.43 \%$ to $16.18 \%$ with $0.75 \%$ increase. This shows that with the increase in $\mathrm{Re}$, the percentage reduction in melting time also decreases.

\subsection{Variation of L/D Ratio}

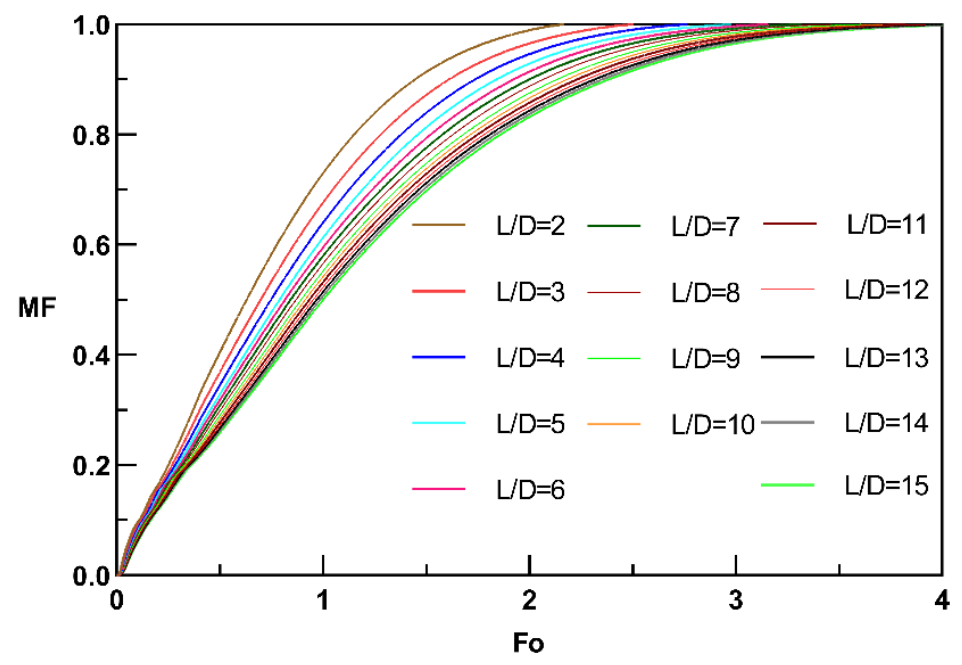

Fig. 14. Fo Vs. MF Variation with L/D ratio

In this work, the L/D ratio is varied from 2 to 15 in steps of 1 by varying length and keeping diameter constant. Other non-dimensional parameters kept constant at $\mathrm{St}=0.5, \mathrm{Ra}=15.32 \times 10^{5}$ and $\mathrm{Re}=1500$.

From Fig. 14, it can be observed that with an increase in the L/D ratio, the non-dimensional melting time has increased. This is obvious because, as L/D increases with D being constant, the volume of PCM increases. As PCM volume increases, the time for melting it also increases. 
$\mathrm{L} / \mathrm{D}$ is different from the other three parameters. While L/D increase resulted in $\mathrm{Fo}_{\mathrm{cm}}$ increase, increase in $\mathrm{Ra}$, St, Re resulted in $\mathrm{Fo}_{\mathrm{cm}}$ decrease. Fig. 15 shows that a maximum increase of $92.98 \%$ is recorded when L/D raised from 2 to 15 . In the same bar chart, from $\mathrm{L} / \mathrm{D}=3$ to $\mathrm{L} / \mathrm{D}=9$, the present case to previous case increase is greater than $6 \%$. After $L / D=9$, the case after case increase is less than $6 \%$.

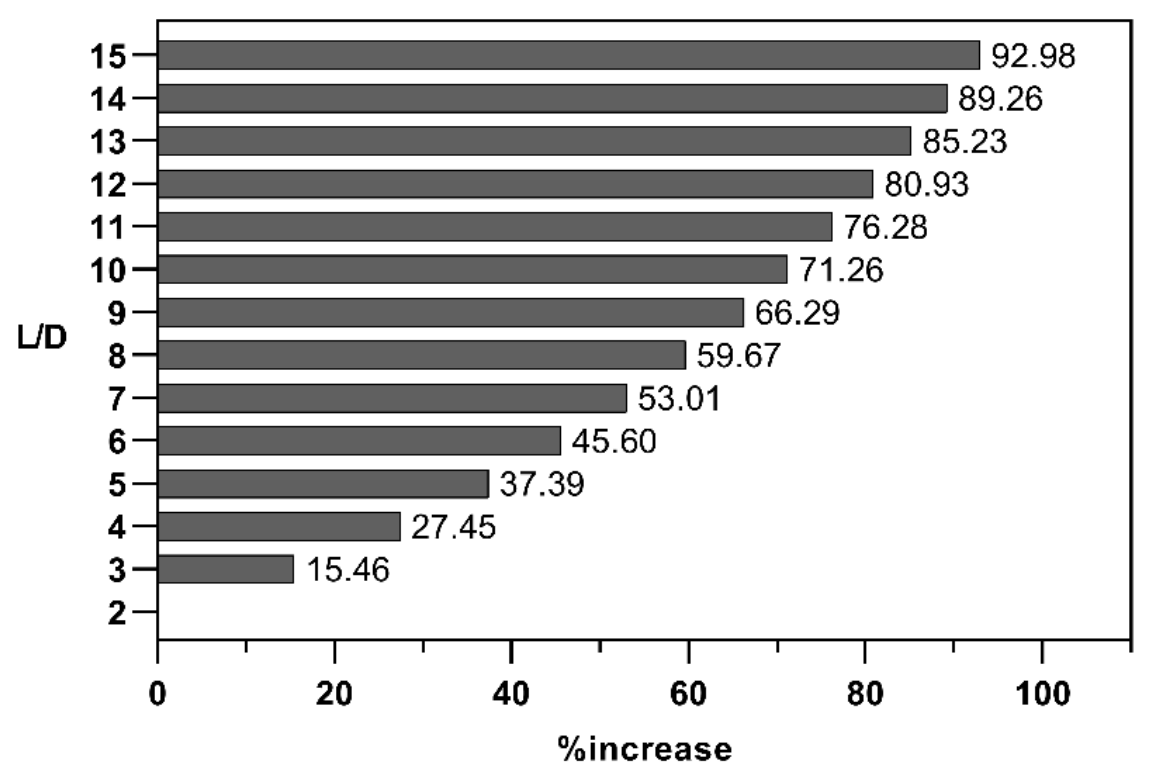

Fig. 15. Percentage increase in $\mathrm{Fo}_{\mathrm{cm}}$ w.r.t $\mathrm{L} / \mathrm{D}=2$ 


\subsection{Correlation for MF}

$$
M F=\frac{C \cdot S t^{A} R a^{B} R e^{D} F o^{E}}{(L / D)^{F}}
$$

Table.3. Power and constant values for MF correlation Eq.23

\begin{tabular}{|c|c|c|c|c|c|c|c|c|}
\hline & Constant & $\mathrm{St}^{\wedge}$ or $\mathrm{St}^{\star \wedge}$ & $\mathrm{Ra}^{\wedge}$ & $\operatorname{Re}^{\wedge}$ & $\mathrm{Fo}^{\wedge}$ & $\mathrm{L} / \mathrm{D}^{\wedge}$ & \multirow[t]{2}{*}{$\mathrm{R}$ square } \\
\hline & & $\mathrm{C}$ & A & B & $\mathrm{D}$ & $\mathrm{E}$ & $\mathrm{F}$ & \\
\hline \multirow{2}{*}{$\begin{array}{c}\text { if } \\
0 \leq \mathrm{MF}<0.8\end{array}$} & For St & 0.1269 & 0.7015 & 0.0963 & 0.1297 & 0.8739 & 0.1835 & 0.9980 \\
\hline & For St* & 0.1482 & 0.9298 & 0.0962 & 0.0976 & 0.8729 & 0.18305 & 0.9975 \\
\hline \multirow{2}{*}{$\begin{array}{c}\text { if } \\
0.8 \leq \mathrm{MF} \leq 1\end{array}$} & For St & 0.5006 & 0.2566 & 0.0321 & 0.0299 & 0.3052 & 0.0734 & 0.9579 \\
\hline & For St* & 0.5316 & 0.3331 & 0.0335 & 0.015 & 0.3011 & 0.07267 & 0.9521 \\
\hline
\end{tabular}

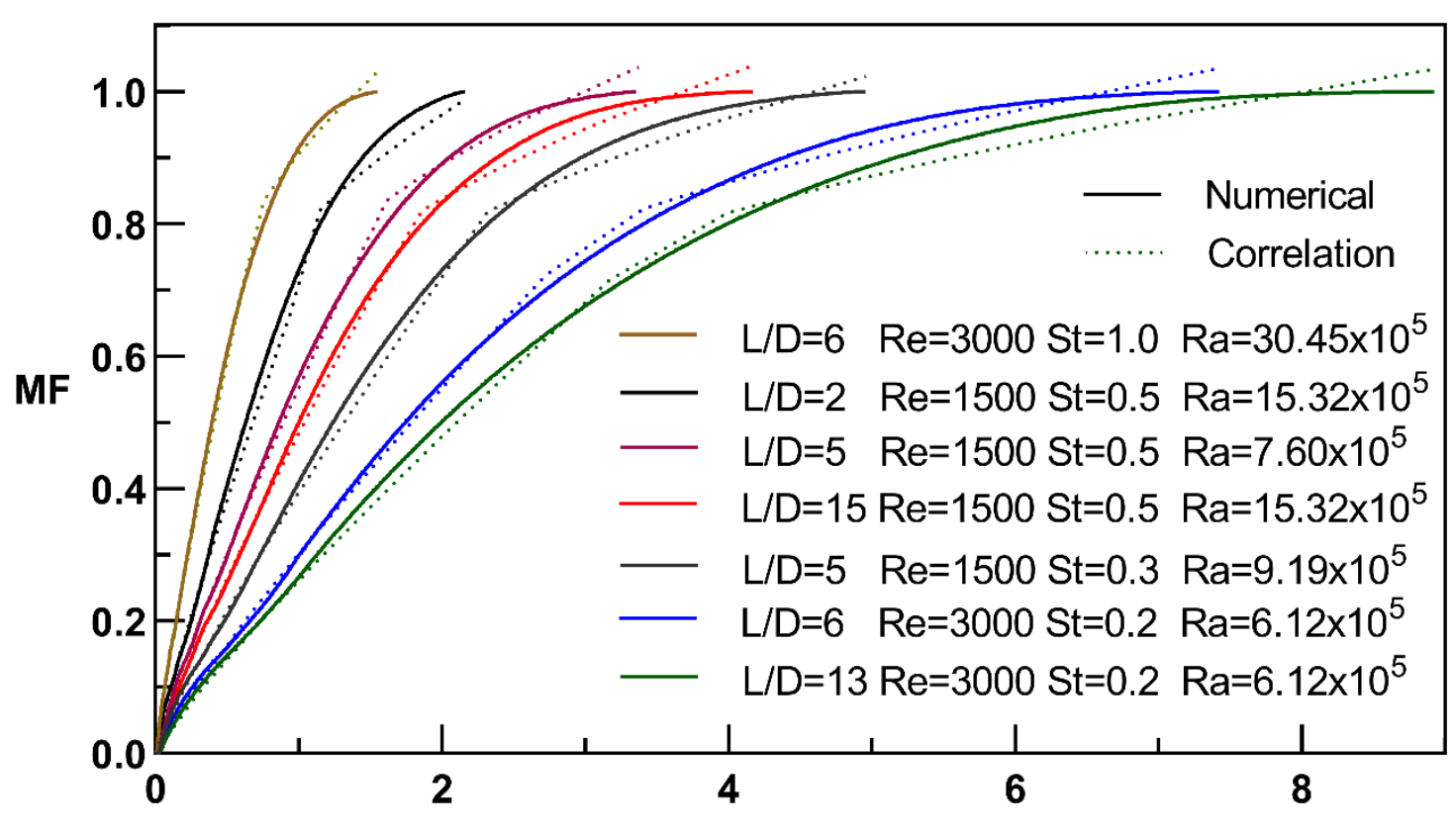

Fo

Fig. 16. Comparison of Correlation with Numerical variation

Multi Linear Regression is performed to obtain correlations in the form of Eq23. As the plots (Fig.7, Fig.9, Fig.11, Fig.12, Fig.14) suggest, the variation of MF till 0.8 is following one particular trend. Whereas, after 0.8 , till 1 , the trend is completely changed. Based on this, for MF less than 0.8 , one correlation is obtained, and for MF greater than 0.8 , a similar correlation with the same variables and different values in the power of those variables is obtained (Table.3).

$$
\mathrm{St}^{*}=\frac{C_{p_{s}}\left(T_{m}-T_{\text {ini }}\right)+C_{p_{l}}\left(T_{\text {inlet }}-T_{m}\right)}{L}
$$


$\mathrm{St}^{*}$ is modified Stefan number, which takes the initial temperature of PCM into consideration. To include this effect, correlations are also considered with $\mathrm{St}^{*}$ replacing St. As Table. 3 hints, for the given MF range, the power values $(\mathrm{B}, \mathrm{E}, \mathrm{F})$ and constant values $(\mathrm{C})$ are close to each other for both St and $\mathrm{St}^{*}$ cases, except for St or $\mathrm{St}^{*}(\mathrm{~A})$ and $\mathrm{Re}(\mathrm{D})$.

Fig. 16 shows the comparison of a few numerical cases with correlation. It points to the good agreement of Correlation with the Numerical data. The $\mathrm{R}$ square values (Table.3) also confirm that the variation is minimal.

\subsection{Correlation for $\mathrm{Fo}_{\mathrm{cm}}$}

$$
F o_{\mathrm{cm}}=\frac{G(L / D)^{H}}{\mathrm{St}^{J} \operatorname{Ra}^{K} \operatorname{Re}^{L}}
$$

Table.4. Power and constant values for $\mathrm{Fo}_{\mathrm{cm}}$ correlation Eq.24

\begin{tabular}{|c|c|c|c|c|c|c|}
\hline & Constant & $\mathrm{L} / \mathrm{D}^{\wedge}$ & $\mathrm{St}^{\wedge} / \mathrm{St}^{\star \wedge}$ & $\mathrm{Ra}^{\wedge}$ & $\mathrm{Re}^{\wedge}$ & \multirow{2}{*}{$\mathrm{R}$ square } \\
\cline { 2 - 6 } & $\mathrm{G}$ & $\mathrm{H}$ & $\mathrm{J}$ & $\mathrm{K}$ & $\mathrm{L}$ & \\
\hline For St & 12.5587 & 0.3019 & 0.8355 & 0.1289 & 0.0892 & 0.9995 \\
\hline For $\mathrm{St}^{*}$ & 10.4929 & 0.3027 & 1.1004 & 0.1343 & 0.0411 & 0.9984 \\
\hline
\end{tabular}

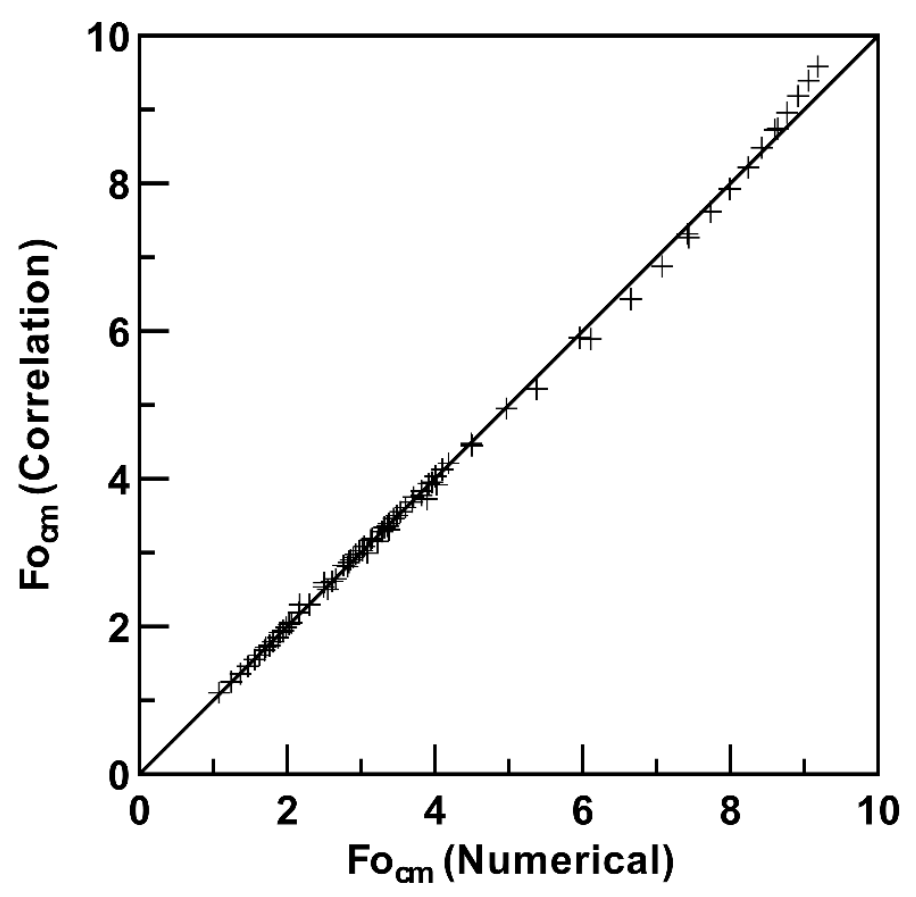

Fig. 17. Comparison of $\mathrm{Fo}_{\mathrm{cm}}$ (Numerical) with $\mathrm{Fo}_{\mathrm{cm}}$ (Correlation)

Eq.24 is the correlation for predicting the non-dimensional melting time, where $\mathrm{G}$ is the constant value and $\mathrm{H}, \mathrm{J}, \mathrm{K}, \mathrm{L}$ are power values. Table.4 
shows the values in the case of St and $\mathrm{St}^{*}$. Fig. 17 indicates that the $\mathrm{Fo}_{\mathrm{cm}}$ computed values are close to the numerically obtained $\mathrm{Fo}_{\mathrm{cm}}$ values. $\mathrm{R}$ square values further validates the same.

It is to be noted that the $\mathrm{Fo}_{\mathrm{cm}}$ correlation is simpler compared to the $\mathrm{MF}$ correlation. This is expected because MF correlation has considered additional continuous variable $\mathrm{MF}$. On the other hand, $\mathrm{Fo}_{\mathrm{cm}}$ correlation considered that MF is constant and equal to one. A similar tendency is evident with the correlations in the first section of this work.

\section{Conclusions:}

Parametric Analysis is conducted on PCM based concentric tube heat exchanger. A validated numerical model is used to predict PCM's melt fraction and dimensionless melting time.

Rayleigh number is varied from $3.04 \times 10^{5}$ to $65.75 \times 10^{5}$. A maximum decrease of $45.79 \%$ is observed in non-dimensional melting time (Fourier Number). Ra trend pointed to the increased influence of Buoyancy.

Stefan Number is varied from 0.2 to 1 . " $\mathrm{Fo}_{\mathrm{cm}} \cdot \mathrm{Ra}$ ".1215" is used to neutralize the effect of simultaneous Rayleigh variation. While $78.22 \%$ of percentage reduction in Fourier Number is recorded, $73.54 \%$ is the exclusive effect of Stefan Number, and the remaining $4.68 \%$ is attributed to Rayleigh Number. Thus, Stefan Number is established as the primary factor influencing the melting time.

Reynolds Number is varied from 600 to 3000. This decreased the melting time only by $16.18 \%$. Hence the influence of Re is not as great as the influence of Rayleigh Number and Stefan Number on the PCM melting.

$\mathrm{L} / \mathrm{D}$ ratio is varied from 2 to 15 . Among the parameters investigated, $\mathrm{L} / \mathrm{D}$ is the only parameter that has witnessed an increase in the melting time with its rise.

The proposed correlations predictions are convincing for quantifying Melt Fraction and dimensionless melting time.

\section{Acknowledgement}

The corresponding author gratefully acknowledges the support of VNRVJIET during the execution of this work.

\section{References}

[1]. Riley, D. S., F. T. Smith, and G. Poots. "The inward solidification of spheres and circular cylinders." International Journal of Heat and Mass Transfer 17, no. 12 (1974): 1507-1516.

[2]. Solomon, A. D. "Melt time and heat flux for a simple PCM body." Solar Energy 22.3 (1979): 251-257. 
[3]. Hasan, Afif. "Phase change material energy storage system employing palmitic acid." Solar energy 52.2 (1994): 143-154.

[4]. Hasan, Afif. "Thermal energy storage system with stearic acid as phase change material." Energy Conversion and Management 35.10 (1994): 843-856.

[5]. Voller, Vaughan R., and M. Cross. "Estimating the solidification/melting times of cylindrically symmetric regions." International journal of heat and mass transfer 24.9 (1981): 1457-1462.

[6]. Rathod, Manish K., and Jyotirmay Banerjee. "Thermal performance of a phase change material-based latent heat thermal storage unit." Heat Transfer-Asian Research 43.8 (2014): 706-719.

[7]. Rathod, Manish K., and Jyotirmay, Banerjee. "Development of correlation for melting time of phase change material in latent heat storage unit." Energy Procedia 75 (2015): 2125-2130.

[8]. Kalapala, Lokesh, and Jaya Krishna Devanuri. "Parametric investigation to assess the melt fraction and melting time for a latent heat storage material based vertical shell and tube heat exchanger." Solar Energy 193 (2019): 360-371.

[9]. Ho, C-J., and R. Viskanta. "Heat transfer during melting from an isothermal vertical wall." (1984): 12-19.

[10]. Fan, Li-Wu, et al. "Heat transfer during melting of graphenebased composite phase change materials heated from below." International Journal of Heat and Mass Transfer 79 (2014): 94104.

[11]. Xu, Yang, et al. "Melting performance enhancement of phase change material by a limited amount of metal foam: Configurational optimization and economic assessment." Applied energy 212 (2018): 868-880.

[12]. Longeon, Martin, et al. "Experimental and numerical study of annular PCM storage in the presence of natural convection." Applied energy 112 (2013): 175-184.

[13]. Voller, V., and C. Prakash. "A fixed grid numerical modeling methodology for convection diffusion mushy region phase-change problem." International Journal Heat Mass Transfer 30.9 (1987): 17091719.

[14]. Beckermann, C., and R. Viskanta. "Natural convection solid/liquid phase change in porous media." International journal of heat and mass transfer 31.1 (1988): 35-46.

[15]. Hameter, Michael, and Heimo Walter. "Influence of the mushy zone constant on the numerical simulation of the melting and solidification process of phase change materials." Computer Aided Chemical Engineering. Vol. 38. Elsevier, 2016. 439-444. 
[16]. Kumar, Mathura, and D. Jaya Krishna. "Influence of mushy zone constant on thermohydraulics of a PCM." Energy Procedia 109 (2017): 314-321.

[17]. Lanka Sandeep Raj, Durga Prasad Bandaru, and Sreenivasulu Sane. "Experimental study of density effect and natural convection in a latent heat storage unit with paraffin wax and air." Energy Storage 3.3 (2021): e226.

[18]. ANSYS Fluent Theory Guide Release 19.1.

\section{Statements \& Declarations}

\section{Funding}

The authors declare that no funds, grants, or other support were received during the preparation of this manuscript.

\section{Competing Interests}

The authors declare that they have no known competing financial interests or personal relationships that could have appeared to influence the work reported in this paper.

\section{Author Contributions}

All authors contributed to the study conception and design. The first draft of the manuscript was written by Lanka Sandeep Raj and all authors commented on previous versions of the manuscript. All authors read and approved the final manuscript. 


\section{Nomenclature}

\section{Dimensionless parameters}

$\begin{array}{ll}\text { St } & \text { Stefan Number } \\ \text { St* } & \text { Modified Stefan Number } \\ \text { Ra } & \text { Rayleigh Number } \\ \text { Re } & \text { Reynolds Number } \\ \text { Fo } & \text { Fourier Number } \\ \text { L/D } & \text { Length to Diameter ratio of Shell } \\ \text { MF } & \text { Melt Fraction }\end{array}$

\section{Properties of PCM and HTF}

$\mathrm{C}_{\mathrm{p}}$

$\rho$

$\mathrm{L}$

Tinlet

$\mathrm{T}_{\mathrm{m}}$

$\mathrm{T}_{\text {ini }}$

a

k

$\beta$

$\mathrm{v}$

$\mu$

$\mathrm{D}_{\text {shell }}$

$\mathrm{R}_{\text {shell }}$

$\mathrm{D}_{\mathrm{o}}$ tube

$\mathrm{R}_{\mathrm{o} \text { tube }}$ $\mathrm{h}$

$\Delta \mathrm{h}$

$\mathrm{p}$

$\mathrm{t}$

g

Specific Heat at constant pressure, J/kg.K

Density, $\mathrm{kg} / \mathrm{m}^{3}$

Latent Heat, J/kg

Inlet temperature of HTF

Melting Temperature of PCM

Initial Temperature of PCM

Thermal Diffusivity, $\mathrm{m}^{2} / \mathrm{s}\left(\rho . \mathrm{C}_{\mathrm{p}} / \mathrm{k}\right)$

Thermal Conductivity, W/m.K

Thermal Expansion Coefficient, $\mathrm{K}^{-1}$

Kinematic viscosity, $\mathrm{m}^{2} / \mathrm{s}$

Dynamic viscosity, Pa.s

Diameter of Shell, m

Radius of Shell, $\mathrm{m}$

Outer diameter inner Tube, $\mathrm{m}$

Radius diameter inner Tube, $\mathrm{m}$

Senible enthalpy, J/kg

Latent enthalpy, $\mathrm{J} / \mathrm{kg}$

Pressure, $\mathrm{Pa}$

Time, s

Acceleration due to gravity, $\mathrm{m} / \mathrm{s}^{2}$

\section{Coordinates in Polar System}

r Radial Dimension

$\theta \quad$ Angular Dimension

$z \quad$ Axial Dimension

\section{Velocities}

$\mathrm{u}$

velocity in r-dimension

$\mathrm{v}$

velocity in $z$-dimension 


\section{Subscripts}

$\begin{array}{ll}\mathrm{s} & \text { solid } \\ 1 & \text { liquid } \\ \mathrm{m} & \text { melting } \\ \mathrm{cm} & \text { complete melting } \\ \mathrm{cs} & \text { complete solidification } \\ \text { ini } & \text { initial }\end{array}$

\section{Correlation glossary}

$\begin{array}{ll}\text { A } & \text { St }\left(\text { or } \mathrm{St}^{*}\right) \text { power in MF correlation } \\ \text { B } & \text { Ra power in MF correlation } \\ \text { C } & \text { Constant in MF correlation } \\ \text { D } & \text { Re power in MF correlation } \\ \text { E } & \text { Fo power in } \mathrm{MF} \text { correlation } \\ \mathrm{F} & \mathrm{L} / \mathrm{D} \text { power in } \mathrm{MF} \text { correlation } \\ \mathrm{G} & \text { Constant in } \mathrm{FO}_{\mathrm{cm}} \text { correlation } \\ \mathrm{H} & \mathrm{L} / \mathrm{D} \text { power in } \mathrm{FO}_{\mathrm{cm}} \text { correlation } \\ \mathrm{J} & \text { St power in } \mathrm{FO}_{\mathrm{cm}} \text { correlation } \\ \mathrm{K} & \text { Ra power in } \mathrm{FO}_{\mathrm{cm}} \text { correlation } \\ \mathrm{L} & \text { Re power in } \mathrm{FO}_{\mathrm{cm}} \text { correlation }\end{array}$

